the graft and as soon as they reach the papillary layer of the cutis vera this activity of the epidermic cells becomes manifest. In those experiments where the graft overlapped the edges of the wound these edges curled up and apparently died, but the portion which was placed in contact with the area from which the granulation tissue had been excised continued to live, became attached to and completely incorporated with it, and in this way brought about the bealing of the wound. The immersion in salt solution of the patches or the drying of them previously to transplantation had little or no effect in destroying the vitality of the epidermis even after so long a time as something like three weeks.

In my own experiments the epidermis was placed under conditions which might be reckoned the most suitable not only for its continuing to live but for reproducing itself. Yet as the account of them conclusively shows, in no case, modify the experiment as I chose, did the epidermis continue even to live beyond a few days, and in some instances after a matter of 14 days not only had the epidermis disappeared but even the true skin had almost entirely vanished. In fact, the whole skin graft had practically entirely disappeared. Apart from the drying and immersion in the various liquids quoted in Ljunggren's and Wentscher's experiments the main difference in their experiments as compared with mine was the fact that the one set of grafts was placed upon an exposed surface while the other set was buried deeply in the underlying tissues or placed in the abdominal cavity. What the difference in the result was due to, why the skin continued to live under such extraordinary circumstances and became incorporated with the surrounding tissues, and why in the other case it invariably died and was absorbed, appear to me a complete mystery. We are almost forced to believe that the exposure on the surface, whatever the influence be which is brought to bear upon the epidermis, is the main factor which determines whether transplanted epidermis will live and grow or not. In Wentscher's experiments it was found that certain islands of epidermis became separated and pushed out from the glands contained in it, but apparently these tend either to come to the surface or die out. Even at some parts of the epidermis thus grafted the rete Malpighii was found to extend downwards in processes for a certain distance, but in none of the cases is it recorder that anything like a cancer tumour resulted. These appearances were nothing more than one sees so frequently in epidermic surfaces under the influence of stimulation.

In conclusion, I have to thank Professor D. J. Hamilton for very valuable help during the above research. I am also indebted to Dr. J. S. H. Walker and Dr. G. M. Duncan for the micro-photographs.

Pathological Laboratory, Aberdeen University.

\section{A CASE OF TUBERCULOUS ISCHIO-RECTAL ABSCESS AND FISTULA, WITH LAR- DACEOUS DISEASE OF THE KIDNEYS.}

By CECIL H. LEAF, M.B. CANTAB., F.R.C.S. ENG., ASSISTANT SURGEON TO THE CANCER HOSPTTAL, BROMPTON, AND TO THE GORDON HOSPITAL FOR DISEASES OF THE RECTUM;

$$
A \times D
$$

H. W. SYERS, M.A., M.D. CANTAB.

PHYSICIAN TO OUT-PATIENTS TO THE GREAT NORTHERN CENTRAL HOSPITAL.

A MAN, aged 32 years, was admitted to the Gordon Hospital on August 29th, 1900, complaining that he suffered a great deal from constipation. He said that from the constant straining efforts which he felt compelled to make he would frequently pass blood which would be followed by diarrhœa or a discharge of mucus and a feeling of soreness. For the last two years the symptoms had been getting worse; the pain on defecation had been intense and the discharge of mucus and diarrhoea had become constant. The patient had been in India for 10 years. Though no definite history of syphilis could be elicited there were two somewhat suspicious-looking scars in the skin over the right side of the liver. He had never had dysentery. An abscess in the right loin had been opened, the scar from the operation being apparent. In both groins there was an enlarged gland. On the left side this was partly caseating, the bluish skin over it being undermined; on the right side, though there was no actual discharge, the skin was adherent, and the gland looked as though it would break down on the slightest provo. cation. The patient was evidently a tuberculous subject.

The operation was performed on Sept. 4th, when a large ischio-rectal abscess on the right side was found which was opened and enlarged and the cavity thoroughly scraped. A small fistulous track ran upwards from the cavity to the interval between the two sphincter muscles on the right side. This was laid open in the usual way. Immediately in front of the lower end of the coccyx a somewhat illdefined thickening of about the size of a hazel nut could be felt in connexion with the walls of the rectum. It was at first difficult to determine whether this thickening had any connexion with the abscess cavity or fistula mentioned above, but eventually it was found possible to pass a probe from the internal opening between the sphincters into the thickening. The intervening track was found to be directed from the right to the posterior aspect of the bowel. This was thoroughly divided with Allingham's scissors, and in so doing the whole of the internal sphincter muscle was divided. The thickening in front of the coccyx was evidently an old abscess cavity, the walls of which had become much indurated. There was little bleeding at the operation. The wound was carefully dressed from the bottom with wool wrung out in a perchloride of mercury lotion (1 in 4000).

On Oct. 13th the wound was looking healthy, though there was still a large unhealed surface over the site of the fistula The patient, who had previously suffered from complete incontinence, was now able to retain his motions for a short time. On the 20th the contraction of the sphincter muscles was good, and the motions could be retained for the greater part of the day. The evening temperature ranged from $99 \cdot 4^{\circ}$ to $100^{\circ} \mathrm{F}$. The wound, which was not yet healed, was dressed with nitrate of silver (four grains to the ounce). The patient subsequently had diarrhœea, and on the 30th the granulating area, though a little less extensive, was not so healthy. The evening temperature remained the same. On Nov. 27th the patient was examined under an anxsthetic, when the ulceration over the site of the operation wound was found to extend upwards for one and a half inches. The patient left the hospital on the 29th having been directed to keep the bowels open, and to have the ulcerated surface dressed twice a day with calomel ointment. On Dec. 14th considerable cedema of the ankles and legs was noticed. The urine was quite clear, its specific gravity being 1015 ; it contained nearly a quarter of albumin. On Jan. 1st, 1901. the odema became general and extended to the face; the eyelids were not much swollen. On the 12th the cedema had entirely subsided, except from the genitals. The urine was still clear and contained about a quarter of albumin. The ulceration in the rectum had almost disappeared, but there was a slight tendency to constriction; the forefinger, however, could easily be admitted. There was no pain on defecation and no incontinence. During February and the early part of March the patient was able to be up for the greater part of the day, and he had no trouble whatever with the rectum. On March 23rd there was a slight discharge from the rectum but no pain on defecation and no stricture. On April 20th the patient complained of intolerable itching all over the body. The scrotum was found to be ulcerated and the left epididymis swollen and painful. The abdomen was large and the odema about the ankles and knees was still apparent. On May 11th the odema became again more marked and the abdomen was larger and a little fluid was present in the abdominal cavity. The urine still retained the same characteristics; its specific gravity was 1015 , it was quite clear and absolutely free from casts, and on boiling it became nearly solid from the large amount of albumin present in it. On the 22nd, after 10 days' complete rest in bed, the odema had again entirely disappeared except from the scrotum and penis, the discharge from the rectum had ceased, there was no pain on defecation, and there was no stricture.

\section{REMARKS.}

With such signs of tuberculous disease it can well be imagined that the patient was not the most favourable subject for operation, yet in spite of this the condition of his rectum has been much improved. Except for a slight discharge - which only comes on after he has been walking 
too much-he suffers no inconvenience, though at one time it seemed almost certain that a stricture would be formed, but this has been prevented by the daily passage of the finger. Another point worth noticing is the fact that though the internal sphincter muscle was completely divided, the patient has now entire control over the bowel, the contraction of both sphincter muscles being extraordinarily good.

From the medical aspect there can, we think, be no doubt that in this case the symptoms were due to the presence of lardaceous degeneration of the kidney. 'The marked cedema, the abundant urine of clear and non-albuminous appearance, the enormous amount of albumin, together with the total absence of casts, all point in this direction. Further, the presence of the more usual forms of nephritis is excluded by the normal condition of the heart and vessels. Reduplication of the first and accentuation of the second sound were altogether absent, and there was no hypertrophy of the left ventricle. The pulse, too, was very far from presenting the qualities found to characterise chronic renal disease.

The case seems to be an important one in the light of the difference of opinion which exists concerning the nature of the renal lesion which accompanies tuberculosis. Quite recently Dr. Landouzy and Dr. Bernard ' published a paper in which they upheld a contention that tuberculosis, pulmonary and other, acts on the kidneys through the effect of the toxins which appertain to the activity of the tubercle bacillus. These authors maintain that the bacillus has no direct action on the kidney structure, but that a chronic inflammatory process is engendered by the "toxin" of the bacillus which eventuates in a chronic parenchymatous nephritis. Quite opposed to this view is that of Dr. A. Brault $^{2}$ who strongly criticises the argument of Dr. Landouzy and Dr. Bernard. He says that there is no evidence whatever of the existence of such a form of nephritis as that described by the writers just named. Dr. Brault attributes all the symptoms referred to by Dr. Landouzy and Dr. Bernard as being the result of the presence of amyloid disease of the kidney. He points out, further, that the so-called "large white kidney" of old days is neither more nor less than this same lardaceous degeneration of the organ. We are in entire accord with Dr. Brault on this subject. We do not accept the arguments which would attribute to tuberculosis of the lungs and other organs the power of initiating kidney changes which are sui generis and are due to the action of a "toxin" of which nothing is known. But as for the "large white kidney"-_a term happily now nearly extinct-we have no doubt at all that it is merely a more or less marked form of amyloid renal disease. It will be noticed that in the present case the symptoms are just those which were formerly attributed to the presence of the "large white kidney"-viz., large quantities of urine and of albumin, much cedema, and considerable pallor. The presence of tuberculous disease no doubt accounts for the lardaceous degeneration of the kidneys, a condition comparatively rare and one which has given rise to great errors, both as regards pathology and diagnosis. For this reason we think that the present case is one of some importance as elucidating a form of renal disease which has given rise to much misconception.

1 La Presse Médicale, March 16th, 1901. 2 Ibid., April 6th, 1901

Infantile Mortality at Bath.-At the meeting of the Bath Sanitary Committee held on June 24th the medical officer of health reported that he had caused leaflets to be distributed in regard to the treatment of children in the city. Dr. Symons added that 31 children had died from diarrhce in 1898 and 30 in 1899, whereas in 1900 only five deaths had occurred from the disease.

Distribution of Charitable Funds. - The assistant commissioner of charity inquiries (Mr. Cardew) has been holding investigations in connexion with the charities of villages near Devizes. At Rowde, one charity bequeathed in 1715 was stated to be disbursed in payments of $8 d$. each to 492 applicants. Mr. Cardew urged the adoption of some different method of distributing the money, such as contributing to a local hospital where the parishioners in need of medical and surgical treatment could receive treatment.

\section{THE PHYSICAL CAUSES OF THE SLIGHTER FORMS OF MENTAL DEFECTS IN CHILDREN.'}

\author{
BY FRANK M. POPE, M.D.
}

IN 1899 the Elementary Education (Defective and Epileptic Children) Act was passed, entitled, "An Act to make better provision for the Elementary Education of Defective and Epileptic Children in England and Wales." This Act empowers school authorities (1) to ascertain what children in their district not being merely dull or backward and not being imbecile are defective-that is to say, what children by reason of mental or physical defect are incapable of receiving proper benefit from the instruction in public elementary schools, but are not incapable by reason of such defect of receiving benefit from instruction in special schools; and (2) what epileptics are capable of receiving benefit. The State thus did for mentally defective children what it had previously done for the deaf and dumb and the blind.

The duty of deciding as to what children came under the above definition was given to approved medical men, examination by whom was made compulsory, and the school age of such children was raised to 16 years. I was appointed to act in this manner for the Leicester School Board and have in consequence examined a large number of children. After doing this I looked up the literature on the subject, more particularly the work ${ }^{2}$ and reports ${ }^{3}$ referred to below, and Dr. F. Warner's article in "Allbutt's System of Medicine." In the report of the Committee there is an immense mass of statistics, over 100,000 children of every degree of mental capacity having been examined. The direction the inquiry had taken was mainly that of observing the conditions of the children with regard to bodily development and defects. The former was in many cases found to be imperfect and the latter were frequent, and the conclusion sought to be enforced appeared to be that the physical defects and socalled abnormal nerve signs were on the whole an index of the accompanying mental defect if any. Abnormal nerve signs are the conditions of expression, tone of facial muscles, "position of hands," tremor, "response to action," and others, and the remark is made that observers in this field must depend for any good results on inspection mainly, this being thought to give better results than the appraisement of the mental deficiency by interrogation of the child. The physical defects to which the observers attached most significance were cranial abnormalities-large heads, small heads, cranial bọsses (rickets), defect of forehead, frontal ridges, and head asymmetrical ; defective ears (external) ; palate-higharched, V-shaped, cleft and others; defective nasal bones and general debility. The correlation of these two classes of signs is made the criterion of mental defect. I reserve my criticisms on these reports till later, only remarking here (1) that Dr. Warner acknowledges that some dull children have no defect and that some children with these signs are not dull ; (2) that there is an underlying assumption throughout the report that these signs are those of degeneration; and (3) that Dr. Warner says that these signs appear to be inherited. Their conclusions appear to be mainly that physical conditions are an index of mental ones, that both should be looked for, and that no risk should be run of neglecting children who exhibit defects. As a practical outcome of the Committee's labours the Act of 1899 was passed. I do not know that one can blame these committees for not having investigated the causes of such defects. If it was the case that they did not examine the children closely, as for cardiac defects and the like, and that they were not supplied with family histories, it is obvious that they were not in a position to undertake the inquiry. Under the Act of 1899 the medical officers have the opportunities which were wanting to these committees. The parents are usually seen and the children can be closely and carefully examined. After making many

I Thesis for degree of M.D. in the University of Cambridge 2 Shuttleworth : Mentally Deficient Children, second edition (Lewis,

3 Report on the Scientific Study of the Mental and Physical Conditions of Childhood (Charity Organisation Society, London, 1895).

4 Clifford Allbutt: A System of Medicine, vol. viii. (London Macmillan, 1899). 